\title{
Factors impacting the formation of 3-MCPD esters and glycidyl esters during deep fat frying of chicken breast meat
}

\begin{abstract}
The effect of the frying temperature, frying duration and the addition of $\mathrm{NaCl}$ on the formation of 3-monochloropropane-1,2-diol (3-MCPD) esters and glycidyl esters (GE) in palm olein after deep frying was examined in this study. The eight frying systems were deepfat frying (at 160 and $180{ }^{\circ} \mathrm{C}$ ) of chicken breast meat (CBM) (with 0, 1, 3 and 5\% sodium chloride, $\mathrm{NaCl}$ ) for $100 \mathrm{~min} /$ day for five consecutive days. All oil samples collected after each day were analyzed for 3-MCPD ester, GE, and free fatty acid (FFA) contents, specific extinctions at 232 and $268 \mathrm{~nm}$ (K 232 and K 268), p-anisidine value (pA), and fatty acid composition. There was a significant $(\mathrm{p}<0.05)$ decrease in the 3 -MCPD esters and a significant $(\mathrm{p}<0.05)$ decrease in the GE with the increasing of the frying duration. There were significant $(\mathrm{p}<0.05)$ increases in the 3-MCPD esters formed when the concentration of $\mathrm{NaCl}$ increased from 0 to $5 \%$. The addition of $\mathrm{NaCl}$ to the $\mathrm{CBM}$ during deep frying had no significant effect on the GE generation. The FFA contents, K 232 and K 268 and pA showed that all the frying oils were within the safety limit.
\end{abstract}

Keyword: 3-monochloropropane-1,2-diol; Glycidyl esters; Palm olein; Frying 